\title{
ANALYSIS OF SMALL OSCILLATIONS OF COMPLEX ELECTRICAL SYSTEMS
}

\author{
Allaev K.R. ${ }^{1}$, Makhmudov T.F. ${ }^{2}$ \\ ${ }^{1,2}$ Tashkent State Technical University named after Islam Karimov, Power Plants, Networks and Systems Department, \\ Universitetskaya 2, Tashkent,100095, Uzbekistan
}

\begin{abstract}
The article discusses the results of the analysis of the static stability of complex electrical systems. The efficiency of the combined application of the equations of nodal voltages (ENV) and the Lyapunov function in quadratic form for the analysis of small oscillations of the electrical system is shown in the literature, which is called the Allaev method. A joint solution of the equations of nodal voltages and the matrix Lyapunov equation is given, which makes it possible to determine the stability conditions for the electrical system and identify the generator first approaching the stability limit. A study of small oscillations of complex electrical systems, which can be performed in full on the basis of matrix methods, successfully developed in recent decades, is carried out, which is associated with a sharp increase in the speed of computation and the amount of memory of modern computers.
\end{abstract}

\section{Introduction}

The highest danger that disrupts normal power supply is an emergency mode in the electric power system (EPS), called a system accident [9].

To prevent such an emergency mode, it is necessary to constantly assess the static stability of the EPS or its resistance to "small" fluctuations, since it is the violations of such stability that lead to systemic accidents with their negative consequences [11].

The problem of studying the static stability of modern complex electrical systems becomes more complicated due to the presence of weak links in their compositions, the presence of various control devices that prevent the determination of the general setting, units with different time constants, etc. [12]. At present, to solve practical problems, methods are used based on calculating the synchronizing power of one of the power plants of the system, i.e. determining the aperiodic stability under the assumption of the absence of self-swinging [9, 10].

The computational analysis of the static stability of EPS of varying complexity shows that the most rigorous theoretically, convenient for calculations and efficient in terms of results is the use of two fundamental methods the method of Lyapunov functions in quadratic form and the equations of nodal voltages (ENV), which is called the Allaev method in the literature [1, 4]. Moreover, the methods for studying small oscillations taking into account self-swinging are complex, therefore, sufficiently reliable results can be obtained with a rigorous mathematical description of the control system for controlled objects using their parameters and characteristics based on the matrix approach $[7,8]$.

\subsection{Formulation of the problem}

It is known [1-4] that the Lyapunov function in quadratic form for linear differential equations is the only one that provides both necessary and sufficient conditions for the stability of the system under study, when small disturbances arise in it. Therefore, the basis of research in this work is the Lyapunov function in quadratic form and nodal equations, and the subject of research is the linearized differential equations of EPS elements. The matrix equations of the elements of electrical systems, which are the main part of the EPS, are based on the equations of state variables, which are most widely used. The considered matrix equations are used to analyze transient processes and static stability of EPS and to synthesize the optimal parameters of the regulators of synchronous machines operating in a complex electrical system.

The steady-state mode of the studied EPS is determined based on the equations of nodal voltages. The nodal equations, which have a functional relationship between the currents and voltages of the nodes, most fully describe the electrical state of the network of any complexity [5]. In the general case, the nodal equations can be written in the form $[1,5,7]$ :

$\mathrm{YU}=\mathrm{I}+\mathrm{Y}_{\mathrm{i} 0} \mathrm{U}_{0}+\mathrm{J}^{*}$,

where

$$
\mathrm{Y}=\left[\begin{array}{cccc}
\mathrm{y}_{11} & -\mathrm{y}_{12} & \ldots & -\mathrm{y}_{1 \mathrm{n}} \\
-\mathrm{y}_{12} & \mathrm{y}_{22} & \ldots & -\mathrm{y}_{2 \mathrm{n}} \\
-\mathrm{y}_{\mathrm{n} 1} & -\mathrm{y}_{\mathrm{n} 2} & \cdots & \mathrm{y}_{\mathrm{nn}}
\end{array}\right]
$$


conductivity matrix of the system under study; I, $\mathrm{Y}_{\mathrm{i} 0}, \mathrm{~J}^{*}$ matrices, respectively, of the nodal currents, the conductances of the connection with the balancing node, the current sources, which are transverse branches with the given conductances [13].

To solve the nodal equations, we will choose Newton's method in polar coordinates, the advantages of which include the quadratic convergence of iterative processes, the possibility of further use for solving optimization problems and calculating stability [5]. In addition, the node voltages $U_{j}$ and the load angles of the generators $\delta_{j}$, which are used in the Lyapunov equations, determined on the basis of solving the nodal equations, contain all information about the state of the system, no matter how complex it is [6].On the basis of the calculated values of the voltages of the generating units and units containing rotating machines, the positiveness of the matrices of Lyapunov's quadratic forms is sequentially checked. In essence, the task of analyzing the static stability of a complex EPS is reduced to a multiple study of the "generator - bus" circuit, which in practical calculations is described by an equation of the order of no more than 4$15[1]$.

\subsection{Lyapunov function method in quadratic form}

In the classical case, the equations describing the processes in the EPS are homogeneous linear (linearized) differential equations and have the form $[1,2,4,10]$ :

$$
\begin{aligned}
& \frac{\mathrm{dx}_{1}}{\mathrm{dt}}=\mathrm{a}_{11} \mathrm{x}_{1}+\mathrm{a}_{12} \mathrm{x}_{2}+\ldots \ldots \ldots+\mathrm{a}_{1 \mathrm{n}} \mathrm{x}_{\mathrm{n}} \text {; } \\
& \frac{\mathrm{dx}_{2}}{\mathrm{dt}}=\mathrm{a}_{21} \mathrm{x}_{1}+\mathrm{a}_{22} \mathrm{x}_{2}+\cdots \cdots \cdots+\mathrm{a}_{2 \mathrm{n}} \mathrm{x}_{\mathrm{n}} ; \\
& \frac{d x_{n}}{d t}=a_{n 1} x_{1}+a_{n 2} x_{2}+\cdots \cdots \cdots \cdots+a_{n n} x_{n} ;
\end{aligned}
$$

either in matrix form:

\& $=\mathrm{Ax}$,

where

$$
A=\left|\begin{array}{cc}
a_{11} & a_{12} \ldots \ldots \ldots . a_{1 n} \\
a_{21} & a_{22} \ldots \ldots \ldots . a_{2 n} \\
\ldots \ldots \ldots \ldots \ldots \ldots \ldots \ldots . . \\
a_{n 1} & a_{n 2} \ldots \ldots \ldots . . a_{n n}
\end{array}\right|
$$

and $\mathrm{x}^{\mathrm{T}}=\left[\mathrm{x}_{1}, \mathrm{x}_{2}, \ldots, \mathrm{x}_{\mathrm{n}}\right]^{\mathrm{T}}$ - transposed vector of state variables.

To determine stability, use the Lyapunov method and define a function in the form of a positive definite quadratic form

$\mathrm{V}(\mathrm{x})=\mathrm{x}^{\mathrm{T}} \mathrm{Qx}$,

or $\mathrm{V}=\sum_{\mathrm{i}, \mathrm{j}=1}^{\mathrm{n}} \mathrm{q}_{\mathrm{ij}} \mathrm{x}_{\mathrm{i}} \mathrm{x}_{\mathrm{j}}$.

The derivative of this function:

$$
\begin{aligned}
& \frac{d V}{d t}=\frac{d\left(x^{T} Q x\right)}{d t}=\left(\frac{d x}{d t}\right)^{T} Q x+x^{T} Q\left(\frac{d x}{d t}\right)= \\
& =(A x)^{T} Q x+x^{T} Q A x=x^{T} A^{T} Q x+x^{T} Q A x= \\
& =x^{T}\left(A^{T} Q+Q A\right) x .
\end{aligned}
$$

Require the Lyapunov function to satisfy the requirement

$\frac{\mathrm{dV}}{\mathrm{dt}}=-\mathrm{W}$,

where $\mathrm{W}=\mathrm{x}^{\mathrm{T}} \mathrm{Cx}$ - arbitrary positive definite symmetric matrix.

Equating expressions (7) and (8), we obtain the equation: $\mathrm{A}^{\mathrm{T}} \mathrm{Q}+\mathrm{QA}=-\mathrm{C}$.

Equation (9), called the matrix Lyapunov equation, provides the stability condition if the inequalities $\mathrm{V}>0$ and $\&<0$ are simultaneously satisfied in some domain of the space of variables $\left(\mathrm{x}_{1}, \mathrm{x}_{2}, \ldots, \mathrm{x}_{\mathrm{n}}\right)$, including the origin [4].

Note that both matrices $\mathrm{Q}$ and $\mathrm{C}$ are symmetric. Indeed, if the matrix $\mathrm{Q}$ is symmetric, that is, $\mathrm{Q}^{\mathrm{T}}=\mathrm{Q}$, then

$\mathrm{C}^{\mathrm{T}}=-\left(\mathrm{A}^{\mathrm{T}} \mathrm{Q}+\mathrm{QA}\right)^{\mathrm{T}}=-\mathrm{Q}^{\mathrm{T}} \mathrm{A}-\mathrm{A}^{\mathrm{T}} \mathrm{Q}=-\left(\mathrm{A}^{\mathrm{T}} \mathrm{Q}+\mathrm{QA}\right)=\mathrm{C}$

and hence the matrix $\mathrm{C}$ is symmetric.

Since the matrix $\mathrm{Q}$ is symmetric, the Lyapunov equation is equivalent to the system of $n(n+1) / 2$ linear algebraic equations [4].

According to Sylvester's theorem [4, 9], the positivity of the principal diagonal minors of the coefficient matrix $Q$ of the quadratic form (6) is a necessary and sufficient condition for the stability of the system under consideration under small perturbations. For example, for a simple EPS circuit, it looks like this:

$$
\begin{aligned}
& \mathrm{Q}=\left|\begin{array}{lll}
\mathrm{q}_{11} & \mathrm{q}_{12} & \mathrm{q}_{13} \\
\mathrm{q}_{21} & \mathrm{q}_{22} & \mathrm{q}_{23} \\
\mathrm{q}_{31} & \mathrm{q}_{32} & \mathrm{q}_{33}
\end{array}\right|>0, \\
& \text { i.e. } \Delta_{\mathrm{L} 1}=\mathrm{q}_{11}>0, \Delta_{\mathrm{L} 2}=\left|\begin{array}{ll}
\mathrm{q}_{11} & \mathrm{q}_{12} \\
\mathrm{q}_{21} & \mathrm{q}_{22}
\end{array}\right|>0, \\
& \Delta_{\mathrm{L} 3}=\left|\begin{array}{lll}
\mathrm{q}_{11} & \mathrm{q}_{12} & \mathrm{q}_{13} \\
\mathrm{q}_{21} & \mathrm{q}_{22} & \mathrm{q}_{23} \\
\mathrm{q}_{31} & \mathrm{q}_{32} & \mathrm{q}_{33}
\end{array}\right|>0 .
\end{aligned}
$$

Analysis of violation of the condition $\Delta_{\mathrm{L} 1}=\mathrm{q}_{11}>0$ shows that all types of violation of the stability of the electrical system at small oscillations (aperiodic violation, selfexcitation, self-swinging) are contained in $\mathrm{q}_{11}$. All other minors of $\mathrm{Q}$ are positive if $\mathrm{q}_{11}>0$. This condition is satisfied for an EES of arbitrary complexity $[1,7]$.

\subsection{Mathematical model of the electric power system}

The linearized equations of the simplest EPS in the presence of automatic excitation regulators (AER) of proportional or strong action on the synchronous generator have the form $[2,4]$ :

- equation of the relative motion of the rotor of a synchronous machine:

$\mathrm{T}_{\mathrm{j}}\left(\mathrm{d}^{2} \Delta \delta / \mathrm{dt}\right)=-\mathrm{P}_{\mathrm{d}}(\mathrm{d} \Delta \delta / \mathrm{dt})-\Delta \mathrm{P}$

- transient equation in the excitation winding:

$\mathrm{T}_{\mathrm{d} 0}\left(\Delta \mathrm{E}_{\mathrm{q}}^{\prime} / \mathrm{dt}\right)=\Delta \mathrm{E}_{\mathrm{qe}}-\Delta \mathrm{E}_{\mathrm{q}} ;$

- transient equation in the field winding:

$\mathrm{T}_{\mathrm{e}}\left(\Delta \mathrm{E}_{\mathrm{qe}} / \mathrm{dt}\right)=\Delta \mathrm{e}-\Delta \mathrm{E}_{\mathrm{qe}}$;

- converting element equation:

$\mathrm{T}_{\mathrm{c}}(\Delta \mathrm{e} / \mathrm{dt})=\Delta \mathrm{u}-\Delta \mathrm{e} ;$

- measuring element equation: 
$\mathrm{T}_{\mathrm{m}}(\mathrm{d} \Delta \mathrm{u} / \mathrm{dt})=\Delta \mathrm{u}_{\mathrm{G}}-\Delta \mathrm{u}$

- AER equation:

$\Delta \mathrm{e}=\sum_{\mathrm{j}}\left(\mathrm{k}_{0 \mathrm{Pj}} \Delta \mathrm{P}_{\mathrm{j}}+\mathrm{k}_{1 \mathrm{Pj}}\left(\mathrm{d} \Delta \mathrm{P}_{\mathrm{j}} / \mathrm{dt}\right)+\mathrm{k}_{2 \mathrm{Pj}}\left(\mathrm{d}^{2} \Delta \mathrm{P}_{\mathrm{j}} / \mathrm{dt}^{2}\right) ;\right.$

where $-T_{j}, T_{d}, T_{e}, T_{c}, T_{m}$ - constant inertia of the unit, time constants, respectively - field windings with an open winding of the stator, exciter, amplifier element, converting and measuring elements $\left(\mathrm{T}_{\mathrm{m}}=\mathrm{T}_{\mathrm{c}}\right) ; \Delta \delta, \Delta \mathrm{E}_{\mathrm{q}}^{\prime}$, $\Delta \mathrm{E}_{\mathrm{q}}, \Delta \mathrm{E}_{\mathrm{qe}}, \Delta \mathrm{e}, \Delta \mathrm{u}, \Delta \mathrm{u}_{\mathrm{G}}-$ deviations of the load angle, transient emf, emf idling, emf on the rotor rings, voltage on the plates of the exciter and the voltage on the generator tires; $\Delta \mathrm{P}_{\mathrm{j}}$ - mode parameters, which is used to control the excitation of the generator; $\mathrm{P}_{\mathrm{d}}-$ damping factor; $\mathrm{k}_{0 \mathrm{Pj}}, \mathrm{k}_{1 \mathrm{Pj}}, \mathrm{k}_{2 \mathrm{Pj}}$ - gain factors for the AEC control channels, respectively, for the deviation, for the first and second derivatives of the mode parameters. Deviations of the regulated parameter of the generator mode or system are determined by the expression:

$\Delta \mathrm{P}_{\mathrm{j}}=(\mathrm{dP} / \mathrm{d} \delta) \Delta \delta+\left(\Delta \mathrm{P}_{\mathrm{j}} / \mathrm{dE}_{\mathrm{q}}\right) \Delta \mathrm{E}_{\mathrm{q}}$.

\subsection{Numerical results}

Consider the application of the equations of the nodal voltage and the Lyapunov function in quadratic form using the example of a three-node circuit (Fig. 1). As a balancing one, we will choose a zero node, the first and third nodes are generating, the second node is load.

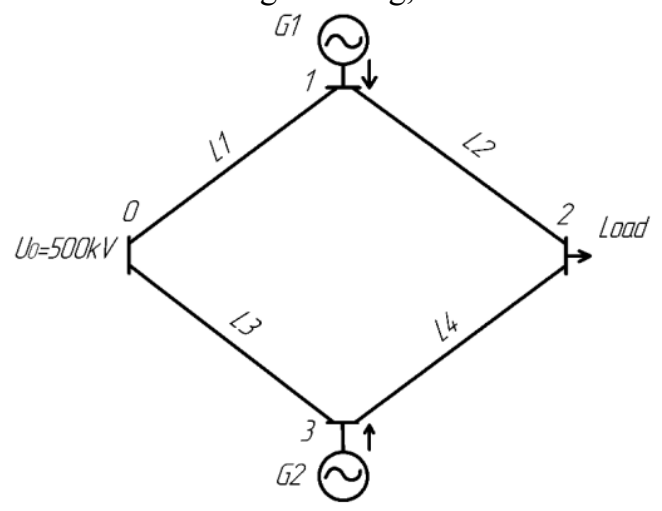

Fig. 1. Schematic diagram of a three-node electrical system

The analysis of the static stability of a complex EPS will be carried out on the basis of known assumptions $[1,12]$ : - when calculating the synchronizing power of any of the generators, the rotor angles of all other generators remain unchanged;

- suppose the emf generators are constant for this mode, the parameters of the equivalent circuit of the electrical system and loads are constant, while the active components of the complex resistances are not taken into account $(\mathrm{r}=0)$;

- in the steady-state mode of operation of a complex system, the power of machines can be expressed through the intrinsic and mutual conductivity of the branches of the equivalent circuit of the electrical system, which are also considered constant.

As is know, to study the static stability of complex systems, a positional mathematical model of EPS is used, which has the form $[1,6,7]$ :
- the system of differential equations of the relative motion of the rotors of synchronous generators are described in the form

$\mathrm{T}_{\mathrm{j} 1} \frac{\mathrm{d}^{2} \delta_{1}}{\mathrm{dt}^{2}}+\mathrm{P}_{\mathrm{d} 1} \frac{\mathrm{d} \delta_{1}}{\mathrm{dt}}=\mathrm{P}_{10}-\mathrm{P}_{1}\left(\delta_{12}, \delta_{13}, \ldots \delta_{1 \mathrm{n}}\right) ;$

$\mathrm{T}_{\mathrm{j} 2} \frac{\mathrm{d}^{2} \delta_{2}}{\mathrm{dt}^{2}}+\mathrm{P}_{\mathrm{d} 2} \frac{\mathrm{d} \delta_{2}}{\mathrm{dt}}=\mathrm{P}_{20}-\mathrm{P}_{2}\left(\delta_{12}, \delta_{13}, \ldots \delta_{1 \mathrm{n}}\right) ;$

$\mathrm{T}_{\mathrm{jn}} \frac{\mathrm{d}^{2} \delta_{\mathrm{n}}}{\mathrm{dt}^{2}}+\mathrm{P}_{\mathrm{dn}} \frac{\mathrm{d} \delta_{\mathrm{n}}}{\mathrm{dt}}=\mathrm{P}_{\mathrm{n} 0}-\mathrm{P}_{\mathrm{n}}\left(\delta_{12}, \delta_{13}, \ldots \delta_{1 \mathrm{n}}\right)$.

- power equations for synchronous generators, expressed in terms of the intrinsic and mutual conductances of the equivalent circuit branches:

$\mathrm{P}_{1}=\mathrm{E}^{2}{ }_{1} \mathrm{y}_{11} \sin \alpha_{11}+\mathrm{E}_{1} \mathrm{E}_{2} \mathrm{y}_{12} \sin \left(\delta_{12}-\alpha_{12}\right)+\ldots+\mathrm{E}_{1} \mathrm{E}_{\mathrm{n}} \mathrm{y}_{1 \mathrm{n}} \sin \left(\delta_{1 \mathrm{n}}-\right.$ $\left.-\alpha_{1 n}\right)$,

$\mathrm{P}_{2}=\mathrm{E}_{2}^{2} \mathrm{y}_{22} \sin \alpha_{22}+\mathrm{E}_{1} \mathrm{E}_{2} \mathrm{y}_{12} \sin \left(\delta_{12}-\alpha_{12}\right)+\ldots+\mathrm{E}_{2} \mathrm{E}_{\mathrm{n}} \mathrm{y}_{2 \mathrm{n}} \sin \left(\delta_{2 \mathrm{n}^{-}}\right.$ $\left.-\alpha_{2 n}\right)$,

$P_{n}=E_{n n}^{2} y_{n n} \sin \alpha_{n n}+\sum_{i \neq j}^{n} E_{i} E_{j} y_{i j} \sin \left(\delta_{i j}-\alpha_{i j}\right)$,

where $\delta_{\mathrm{i}}$ and $\delta_{\mathrm{ij}}$ - absolute and relative load angles of generators; $E_{i}-$ generator electromotive forces; $T_{j}-$ constant inertia of aggregates; $\mathrm{P}_{\mathrm{di}}-$ generator equivalent damping factors; $\mathrm{P}_{\mathrm{i}}$ - electromagnetic powers of synchronous generators; $\mathrm{y}_{\mathrm{ii}}, \mathrm{y}_{\mathrm{ij}}-\mathrm{own}$ and mutual conductivities of the system; $\alpha_{\mathrm{ii}}$ и $\alpha_{\mathrm{ij}}-$ corresponding padding angles.

Below are the initial data and parameters of a complex electrical system (Fig. 1).

Parameters of nodes:

G1: $P_{\mathrm{G} 1}=300 \mathrm{MW} ; \cos \varphi_{\mathrm{G} 1}=0.8 ; \mathrm{U}_{\mathrm{G} 1}=500 \mathrm{kV} ; \mathrm{T}_{\mathrm{j} 1}=6 \mathrm{sec}$.; $\mathrm{x}_{\mathrm{d} 1}=1.907 ; \mathrm{x}_{\mathrm{d} 1}^{\prime}=0.278$.

$\mathrm{G} 2: \mathrm{P}_{\mathrm{G} 2}=200 \mathrm{MW} ; \cos \varphi_{\mathrm{G} 2}=0.8 ; \mathrm{U}_{\mathrm{G} 2}=500 \mathrm{kV} ; \mathrm{T}_{\mathrm{j} 2}=5.4 \mathrm{sec}$.; $\mathrm{x}_{\mathrm{d} 2}=1.915 ; \mathrm{x}_{\mathrm{d} 2}^{\prime}=0.275$.

Nodes are interconnected by appropriate overhead transmission lines L1-L4.

L1: $\mathrm{U}_{\mathrm{L} 1}=500 \mathrm{kV} ; \ell_{\mathrm{L} 1}=195 \mathrm{~km} ; \mathrm{r}_{0}=0.0397 \mathrm{Ohm} / \mathrm{km}$; $\mathrm{x}_{0}=0.31 \mathrm{Ohm} / \mathrm{\kappa м}$.

L2: $\mathrm{U}_{\mathrm{L} 2}=500 \mathrm{kV} ; \ell_{\mathrm{L} 2}=115 \mathrm{~km} ; \mathrm{r}_{0}=0.0362 \mathrm{Ohm} / \mathrm{km}$; $\mathrm{x}_{0}=0.306 \mathrm{Ohm} / \mathrm{km}$.

L3: $\mathrm{U}_{\mathrm{L} 3}=500 \mathrm{kV} ; \ell_{\mathrm{L} 3}=180 \mathrm{~km} ; \mathrm{r}_{0}=0.0397 \mathrm{Ohm} / \mathrm{km}$; $\mathrm{x}_{0}=0.31 \mathrm{Ohm} / \mathrm{km}$.

L4: $\mathrm{U}_{\mathrm{L} 4}=500 \mathrm{kV} ; \ell_{\mathrm{L} 4}=175 \mathrm{~km} ; \mathrm{r}_{0}=0.0397 \mathrm{Ohm} / \mathrm{km}$; $\mathrm{x}_{0}=0.31 \mathrm{Ohm} / \mathrm{km}$.

Load node parameters:

$\mathrm{P}_{\text {Load }}=150 \mathrm{MW} ; \cos \varphi_{\text {Load }}=0.88 ; \mathrm{U}_{\text {Load }}=500 \mathrm{kV}$.

Generators are equipped with automatic excitation regulators that react to the deflection and the first derivative of the angle, as well as to the voltage deviation. Perform the calculation of the steady state and check the positivity of the first minor $\mathrm{q}_{11}$ of the matrix of the quadratic form $\mathrm{Q}$ for generating nodes.

The results of the calculation of the steady state (modules of the voltage nodes and the angles of the load):

$\&_{1}=505,2 \mathrm{e}^{\mathrm{j} 15^{\circ}} \mathrm{kV}, \&_{2}=496,2 \mathrm{e}^{\mathrm{j} 34^{\circ}} \mathrm{kV}, \&_{3}^{\&}=509,8 \mathrm{e}^{\mathrm{j} 23^{\circ}} \mathrm{kV}$ Then, using the obtained data, solve the equation of the Lyapunov function in quadratic form with respect to the above systems of equations (9). 
The calculation is carried out with a heavier mode - a gradual increase in the active load power from $\mathrm{P}_{\text {Load }}=150 \mathrm{MW}$ to $\mathrm{P}_{\text {Loadmax }}=200 \mathrm{MW}$, which led to an increase in the load angles of the generators, respectively, to $\delta_{\mathrm{cr} 1}=126^{\circ}$ and $\delta_{\mathrm{cr} 2}=131.5^{\circ}$.

As seen from Fig. 2, the characteristic of variation of the minor $\mathrm{q}_{11}$ of the first generator $\mathrm{G} 1$ depending on the angle $\delta$ first approaches the stability limit.

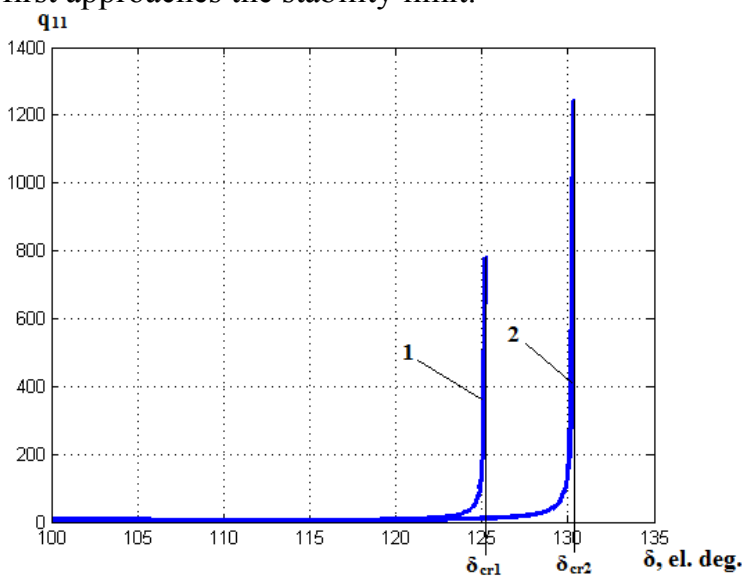

Fig. 2 Changes of the first diagonal minor $\mathrm{q}_{11}$ of the matrix $Q$ of the Lyapunov function in quadratic form depending on the angle $\delta$ :

1-characteristic G1; 2-characteristic G2

\section{Conclusion}

1. The stability of an electrical system of any complexity with small deviations is characterized by the positiveness of the first minor of the matrix of the quadratic form $\mathrm{q}_{11}>0$ of the Lyapunov function in the quadratic form. Moreover, it is shown that if $\mathrm{q}_{11}>0$, then all other minors of $\mathrm{Q}$ are positive. Therefore, the study of the stability of an EPS of arbitrary complexity can be limited to investigating only the condition $\mathrm{q}_{11}>0$. We called this criterion simplified $[1,7]$, since the positiveness of $\mathrm{q}_{11}$ determines the positiveness of the remaining higher minors of the matrix, and therefore only this condition is considered. It is important that the condition $\mathrm{q}_{11}>0$ contains theoretically known types of violation of the stability of an electrical system under small disturbances (aperiodic violation, self-excitation, self-swinging), therefore, contains both necessary and sufficient conditions for stability.

2. Analytically and computationally, the i-th generator of a complex electrical system is the first to approach the stability limit.

According to the authors, studies of small oscillations of an electrical system based on Lyapunov functions in quadratic form should be developed and carried out in the following directions:

- improvement of the model of nodal voltages equations for joint application with the Lyapunov function in quadratic form;

- development of a more accurate model of the electrical system;

- development of matrix methods for aggregate and interconnected optimal control between stations of the electrical system;
- development of an algorithm and a model for optimal control, assessment and synthesis of the corresponding control laws for EPS with the probabilistic nature of the initial information.

\section{References}

1. Allaev K.R., Mirzabaev A.M. Small oscillations of electrical systems (Matrix approach), $\mathrm{T} \quad \therefore$ Fan va tehnologiya, 2011, - $325 \mathrm{p}$.

2. Allaev K., Makhmudov T. Prospects of diversification and ensuring energy safety of Uzbekistan. E3S Web Conf., Volume 139, 2019, Rudenko International Conference "Methodological problems in reliability study of large energy systems" (RSES 2019).

https://doi.org/10.1051/e3sconf/201913901002

3. Anderson PM, Fouad AA. Power system control and stability, Second edition, Willey-Interscience A John Wiley \& Sons Inc, USA; 2003.

4. Kunder P. Power system stability and control, McGraw-Hill, Inc., USA; 1994.

5. Norelys A-C, Manuel D-M, Javier AG, Rafael C-L. Using general quadratic Lyapunov functions to prove Lyapunov uniform stability for fractional order systems. Communications in Nonlinear Science and Numerical Simulation. 2014; 22: 1-3.

https://doi.org/10.1016/j.cnsns.2014.10.008.

6. Abdellatif BM. Stability with respect to part of the variables of nonlinear Caputo fractional differential equations. Mathematical Communications. 2018; 23: 119-126.

7. Allaev K., Makhmudov T. Research of small oscillations of electrical power systems using the technology of embedding systems. Electrical Engineering, 2020; Issue 1: 309-319.

DOI 10.1007/s00202-019-00876-9

8. Mirzabaev A.M. Matrix methods and algorithms for the analysis of static stability of electrical systems: Abstract of the dissertation of Doctor of Technical Sciences. - T.: 2016 .- 82p.

9. Automation of dispatch control in the power industry. Ed. Yu.N. Rudenko, V.A. Semenova - M .: Publishing house of MEI, 2010, 648p.

10. Allaev KR, Mirzabaev AM. Matrichnye metody analiza malyh kolebaniy elektricheskih system (Matrix methods for the analysis of small oscillations of electrical systems), Fan va texnologiya Publ., Tashkent; 2016, -432 p.

11. Irwanto $M$ et al. Improvement of Dynamic Electrical Power System Stability Using Riccati Matrix Method. Applied Mechanics and Materials. 2015; 793: 29-33. https://doi.org/10.4028/www.scientific.net/AMM.793.29 12. Antonovskaya OG. On the construction of a quadratic Lyapunov function with given properties. Differential Equations. 2013; 49(9): 1187-1191. https://doi.org/10.1134/S0012266113090140.

13. Fazylov HF, Nasyrov TH. Ustanovivshiesya rezhimi elektroenergeticheskih sistem i ih optimizaciya (Established regimes of electric power systems and their optimization), Moliya Publ., Tashkent; 1999. 